\title{
Improving operations management by synthesizing participant knowledge and system data
}

\author{
Etiënne A.J.A. Rouwette \\ Jac A.M. Vennix \\ Methodology Department/ Institute for Management Research \\ Faculty of Management \\ Radboud University Nijmegen \\ Thomas van Aquinostraat 1.2.31 \\ PO Box 9108 \\ 6500 HK Nijmegen \\ The Netherlands \\ tel +31243611468, fax +31243611933 \\ e.rouwette@fm.ru.nl
}

\begin{abstract}
With the advent of Enterprise Resource Planning (ERP) systems, availability of data is no longer the bottleneck to decision making in many organizations. Instead the reverse seems to apply more frequently. Integrated organization-wide computer systems overwhelm managers with data to such an extent that it becomes difficult to assess relevance for managing operations. A number of methodologies attempt to help management to distill meaning from large amounts of data. These methodologies enable managers to identify multiple performance indicators and determine tradeoffs between effects of proposed improvements. Implementation of improvements however entails organizational change. Methodologies are commonly used in an expert mode, which makes them prone to many of the potential traps of change management, such as lack of commitment due to the 'not invented here' syndrome. Alternative methodologies such as group model building enable problem owners to identify problems and combine knowledge and system data in solving these are available. In this paper we explore three group model building projects in an ERP context. We address the context in which the projects were carried out and the process of client participation and model construction. We describe effects in terms of end products, quality of solutions and outcomes of system changes.
\end{abstract}

\section{Motivation}

Decision making in organizations and in operations management in particular, increasingly profits from integrated information systems across the entire organization. Several benefits 
are expected benefits from implementing these Enterprise Resource Planning (ERP) systems. Integration of business processes and integration of key business and management processes is expected to lead to a central overview of organizational affairs. Access to enterprise-wide data which provides information-sharing across business processes contributes to coordination and monitoring of performance in real time (Benders, Batenburg, \& Van der Blonk, 2006). However, these expected benefits are not always realized as implementation of ERP systems is often incomplete. In this sense ERP systems are not unlike other information systems. According to the Standish Group (2003), ICT projects repeatedly fail to deliver: $15 \%$ of projects lead to no result, another $50 \%$ are too expensive, too late and/ or produce outcomes of low quality and only $35 \%$ are successful on all relevant criteria. Several studies are conducted about success and failure of ERP projects (Davenport, 1998; Fahy, 2002; Hall, 2002; Trunick, 1999). Trunick (1999) for example estimates that 40\% of ERP projects are only partly completed and $20 \%$ are a total failure. The reasons for this lack of implementation and ways to change this situation have been studied for a number of years now.

The literature cites human factors as the main reason for implementation failure. In an overview of implementation research, Muscatello and Parente (2006) find that many authors see user related issues, and not the technology itself, as the main causes of failure. Changing over to an ERP system is more than starting to use a new technology. ERP providers maintain that their systems capture the best business experience. An ERP system is thus also a new 'way of doing business' (Mabert, Soni, \& Venkataramanan, 2003), which may threaten the existing power positions of individuals in the organization. ERP systems are an innovation (Benders et al., 2006) and organizational adoption can be slow or incomplete. The most common reason for failure of ERP projects is that end users are not willing to adopt the new system (Nah, Tan, \& The, 2004). ERP providers offer support methods to facilitate implementation of their specific systems (Benders et al., 2006: 199). SAP has developed ASAP (Accelerated SAP) to facilitate implementation of SAP R/3. Oracle has developed FastTrack. The focus of these support methods is on standardizing the implementation trajectory and project management. These methods operate on the premise that the organization will have to adapt to the system, instead of vice versa. In essence approaches such as ASAP and FastTrack are expert based. Amoako-Gyampah (2007) cites evidence that user-focused approaches, such as communication and training programs, increase the use of ERP. A more fundamental way of focusing on the user, user involvement in system development, is potentially even more effective in increasing system use. However, there is a clear tension between implementing best industry practice and involving users in system development. 
While changing the way of doing business is perhaps an effect of ERP systems that is not always expected by their users, systems also offer a challenge to organizations exactly because of their intended use. ERP systems present and integrate enterprise-wide data. In doing so they may overwhelm users and difficult it to separate important from unimportant facts. A client in one of the projects described in this paper formulated this as: 'I am standing up to my knees in data and I have no idea on the structure behind it'. Several methodologies are available to provide and analyze this structure. A generic approach such as the balanced scorecard (Kaplan \& Norton, 1996) facilitates the identification of performance indicators. Other methodologies offer a structure in the form of a simulation model or (qualitative) map of the enterprise. Banker and Kaufmann (2004) discuss the use of discrete event and continuous simulation approaches to information systems development. While these methodologies are commonly used in an expert mode, a number of facilitated modeling approaches are used for information systems development as well. Examples are Soft Systems Methodology (Checkland \& Holwell, 1998; Checkland \& Poulter, 2006) and cognitive mapping (Ackermann \& Eden, 2005). A general discussion on the use of causal mapping for information systems development is given by Hodgkinson and Clarkson (2005). These facilitated modeling approaches clearly surface the opinions of users. They do not directly support contrasting opinions with system data.

In summary, implementation and deducting sensible process improvements from large amounts of data are recurring problems in ERP system use. Approaches develop to tackle the first problem are offered by system providers. These methodologies facilitate implementation by focusing on project management rather than user involvement in system design. The second problem is addressed by approaches such as the balanced scorecard and simulation. These methodologies are expert based. Facilitated modeling approaches are available but do not allow for combining problem owners' opinions with system data. This in effect means that we are loosing out on one of the main strengths of ERP systems. It seems there is room for a methodology that combines user involvement with simulation. Group model building, based on system dynamics, is one of these methodologies. System dynamics originated in the 1950s as industrial dynamics (Forrester, 1958) and has been applied to operations management since. Recently, Milling (1996; Milling, 2002) reviewed its use in innovation processes. Größler, Thun, \& Milling (2008) propose to use system dynamics as a general theory for operations management. Client involvement has been a topic of interest in system dynamics modeling since the 1970s (e.g. Roberts, 1973). A couple of approaches for involving clients have been developed and used in practice (for an overview, see D. F. Andersen, Vennix, Richardson, \& Rouwette, 2007). In this paper we use group model building as a general term for system dynamics modeling in cooperation with clients. Group model building has much in common with other participatory modeling approaches, particularly in operational research. 
Facilitated modeling methods in operational research are commonly called Problem

Structuring Methods (PSMs). Practitioners from the system dynamics and PSM fields have frequently compared their approaches, borrowed from each other's techniques or discussed their methodological assumptions (see for example the papers at the 1994 International System Dynamics Conference, the special issue of System Dynamics Review on group model building, Howick, Ackermann, \& Andersen, 2006; Lane, 1994).

Group model building enables user involvement and the integration of problem owners' opinions with system data. In this paper we focus on the contribution group model building may have in ERP system implementation. Are the expected benefits of group model building realized in an ERP context? Does the generic procedure for group model building need to be adapted in this context? We use three master thesis projects as cases to provide an exploratory answer to these questions. The remainder of this paper is structured as follows. The next section describes our approach to case analysis. An existing framework for reviewing group model building cases, based on a study by Rouwette, Vennix and Van Mullekom (2002) will be used to distill the essential elements of our cases. Following this framework, we then describe the context, process and outcome of the three applications of group model building. We end by listing our conclusions on benefits and process adaptations of group model building in an ERP context.

\section{Approach to case analysis}

Rouwette et al. (2002) have conducted a meta-analysis of 107 cases of client involvement in system dynamics modeling. Following Pawson and Tilley (1997), they argue that modeling interventions may have different impacts because the context in which they are used is subtly different, or because modeling techniques are not exactly similar from one context to another. For instance, a modeling intervention might take place in a politically sensitive situation, in which some participants have double agendas and use the project to advance their own interests. As a result, participants might not reveal all relevant information. Another intervention might focus on an issue in which all participants share an interest and data are readily available. In the first example, an initial simulation model might be built but validation may be incomplete due to a lack of client interest and data availability. In the second case, available data allow the model to be validated and used to test policy options against a variety of scenarios. Clearly the context and process (or mechanism) shape both projects' results. Pawson and Tilley (1997) argue that a realistic accumulation of evaluation studies boils down to discovering which combinations of mechanism and context lead to which outcomes. Hence the second goal of this paper: to produce meaningful and potentially robust 
patterns of interventions, contexts and outcomes. Rouwette et al. (2002) propose the following list of central elements in when analyzing group model building cases:

\section{Context}

- Background: authors, title, source, date publication

- Organization: profit, sector, name and size organization, location, consultant

- Problem: motive, research question and type, importance, implementation expected

Mechanism

- Intervention: techniques used, type of model, phases of modeling and participation, number and functions of participants, sources of information, software and other materials, time span of project

Outcome

- Impact: research design, data collection method, subjects, researchers, time span, way of feedback (report and presentation), outcome variables

We add one additional factor under the header of context: the type of ERP system in the case. In the following, we describe three cases in which ERP users were involved in system dynamics modeling using this framework.

\section{Context}

Context factors for the three cases are listed in the table below. The cases are described in three master theses (Ewalts, 2005; Goedhart, 2002; Venderbosch, 2007) available from Radboud University Nijmegen, The Netherlands. The third case is also reported in a conference paper (Deenen, 2007a) and a master thesis from Delft University (Deenen, 2007b).

\begin{tabular}{|l|l|l|l|}
\hline & Goedhart (2002) & Ewalts (2005) & Venderbosch (2007) \\
\hline $\begin{array}{l}\text { Organization } \\
\text { name }\end{array}$ & $\begin{array}{l}\text { Vinamul Polymers } \\
\text { (National Starch and } \\
\text { Chemical Company) }\end{array}$ & $\begin{array}{l}\text { Akzo Nobel Decorative } \\
\text { Coatings Europe }\end{array}$ & ONEgas (NAM/ Shell) \\
\hline $\begin{array}{l}\text { Organization } \\
\text { type }\end{array}$ & Profit, chemicals & Profit, chemicals & Profit, oil and gas \\
\hline $\begin{array}{l}\text { Organization } \\
\text { size }\end{array}$ & $\begin{array}{l}\text { Parent company 10,000 } \\
\text { employees in 38 } \\
\text { countries, case site } \\
\text { Geleen 140 employees }\end{array}$ & $\begin{array}{l}\text { Parent company 64,000 } \\
\text { employees in 80 } \\
\text { countries, case site } \\
\text { Darwen 650 employees }\end{array}$ & $\begin{array}{l}\text { Parent company } \\
104,000 \text { employees in } \\
\text { Assen 2,500 employees }\end{array}$ \\
\hline ERP & Financial planning & SAP, Mercia & SAP PM module \\
\hline
\end{tabular}




\begin{tabular}{|l|l|l|l|}
\hline Consultant & Author & Author & $\begin{array}{l}\text { Author and second } \\
\text { master student }\end{array}$ \\
\hline $\begin{array}{l}\text { Problem and } \\
\text { research } \\
\text { question }\end{array}$ & $\begin{array}{l}\text { How can judgmental } \\
\text { and quantitative } \\
\text { elements be integrated } \\
\text { in a forecast? }\end{array}$ & $\begin{array}{l}\text { How can logistic } \\
\text { performance be } \\
\text { explained and } \\
\text { improved? }\end{array}$ & $\begin{array}{l}\text { How can corrective } \\
\text { maintenance } \\
\text { performance be } \\
\text { explained and } \\
\text { optimized? }\end{array}$ \\
\hline Problem type & $\begin{array}{l}\text { Explanatory/ } \\
\text { prescriptive }\end{array}$ & $\begin{array}{l}\text { Explanatory/ } \\
\text { prescriptive }\end{array}$ & $\begin{array}{l}\text { Explanatory/ } \\
\text { prescriptive }\end{array}$ \\
\hline $\begin{array}{l}\text { Problem } \\
\text { importance }\end{array}$ & $\begin{array}{l}\text { Project initiated by } \\
\text { client }\end{array}$ & $\begin{array}{l}\text { Project initiated by } \\
\text { client }\end{array}$ & $\begin{array}{l}\text { Project initiated by } \\
\text { client } \\
\text { Importance high } \\
\text { (pretest and posttest) }\end{array}$ \\
\hline
\end{tabular}

Table 1. Context factors

The three modeling cases take place in profit organizations in the production sector. All organizations are divisions of multinationals based in the Netherlands. The information systems in the three cases were a financial planning system, SAP (used in conjunction with Mercia, a forecasting program) and the SAP PM module, respectively. The consultants in all cases were master students with limited experience in system dynamics and group model building, coached by supervisors from Radboud University (and from Delft University in the third case). In the research by Rouwette et al. (2002), research questions were coded as explorative, descriptive, explanatory and/ or prescriptive. In line with most system dynamics modeling efforts, the research questions that prompted the projects contained an explanatory and prescriptive part. In the first case, the research problem concerns the sales an operating planning process of Vinamul Polymers Europe. The financial forecast is critical for completion of the management review but frequently completed behind schedule. The goal of the modeling project is to integrate available system information with judgments by staff for constructing the financial forecast. The second case, at Akzo Nobel, concerns logistical performance. The performance on indicators such as service level, stock level, costs and replenishments lead-time is lower than desired. The quote on the need for structure started off the modeling project in the third case. ONEgas had been using a SAP module supporting the corrective maintenance process for several years, but was not able to identify levers for improving performance.

In all cases the project was initiated by the client organization, indicating that the problem was felt to be important and clients expected results that could be implemented in their 
organization. In the third case participants filled out a pretest and posttest questionnaire. In both the pretest and posttest subjects were asked to rate the importance of the issue to their organization and to them individually. All mean scores are significantly higher than neutral, indicating that the problem is important in the eyes of the participants.

Important similarities between case contexts are the following. In all projects a crucial phase of the firms' operations is modeled. Clients feel the issues are important. Modeling and session facilitation is done by master students with limited experience.

\section{Process}

The central part of the process description by Rouwette et al. (2002) is how the client was involved in the different phases of modeling. Andersen and Richardson have coined the term 'scripts' to refer to specific techniques of involving clients (1997; Luna-Reyes et al., 2006). Scripts are specific parts of modeling sessions in which the consultant and participants interact, usually taking 15 minutes or less. An example of a script that can be used in the phase of problem definition, is eliciting reference modes. Employing this script means that the consultants first asks the group to identify the time horizon of interest for this problem. Second, the group is invited to think of important 'dynamic success measures' that should be or are the focus of management attention. The group then draws the graph over time of the success measure over the specified time horizon. If the same success measure is depicted differently by different group members, this can be the focus of a discussion. Conclusions from the discussion and the completed graphs are used as a basis for the model in the remainder of the project. In addition to scripts (techniques used), the process is also described by listing the type and size of the model, participants involved, sources of information used, software and time span of the project. The following table summarizes the process elements in the three modeling cases.

\begin{tabular}{|l|l|l|l|}
\hline & Goedhart (2002) & Ewalts (2005) & Venderbosch (2007) \\
\hline Techniques & Session 1: preliminary & Interviews on problem & Interviews, \\
model (CLD), CLD & identification on site 1, & Session 1: expectations, \\
interviews and CLDs on & intro SD, problem \\
& Session 2: CLD & site 2 and 3, interviews, & variable, NGT, CLD \\
& Researcher translates & CLD and parameter \\
CLD into spreadsheet & $\begin{array}{l}\text { estimation on site 4, } \\
\text { construction of formal } \\
\text { model on site 5 }\end{array}$ & workflow \\
& & Session 2: s\&f & \\
& & & Researchers formalize \\
\hline
\end{tabular}




\begin{tabular}{|c|c|c|c|}
\hline & & $\begin{array}{l}\text { On site 5: researcher } \\
\text { compares CLDs sites, } \\
\text { interviews } \\
\text { Session 1: preliminary } \\
\text { model (s\&f), } \\
\text { identification main s\&f, } \\
\text { initial formalization, } \\
\text { Session 2: s\&f model, } \\
\text { identification feedback } \\
\text { loops } \\
\text { Formalization by } \\
\text { researcher } \\
\text { Session 3: presentation } \\
\text { and adjustment formal } \\
\text { model } \\
\text { Workbooks }\end{array}$ & $\begin{array}{l}\text { model } \\
\text { Session 3: presentation } \\
\text { and simulation formal } \\
\text { model } \\
\text { Three small sessions on } \\
\text { interventions, scenario } \\
\text { variables and KPIs } \\
\text { Session 4: simulation } \\
\text { interventions and } \\
\text { scenarios } \\
\text { Workbooks }\end{array}$ \\
\hline $\begin{array}{l}\text { Type of } \\
\text { model }\end{array}$ & Quantitative & Quantitative & Quantitative \\
\hline Model size & $\begin{array}{l}\text { Large: top level view } 33 \\
\text { variables, structure } \\
\text { repeated for } 29 \\
\text { customers }\end{array}$ & $\begin{array}{l}\text { Large: top level view } 45 \\
\text { variables, structure } \\
\text { repeated for three } \\
\text { categories of products }\end{array}$ & $\begin{array}{l}\text { Large: top level view } \\
\text { about } 45 \text { variables, } \\
\text { structure repeated for } \\
\text { seven categories of } \\
\text { priorities }\end{array}$ \\
\hline $\begin{array}{l}\text { Phases of } \\
\text { modeling } \\
\text { and } \\
\text { participation }\end{array}$ & $\begin{array}{l}\text { All } \\
\text { Researcher responsible } \\
\text { for formalization, } \\
\text { validation, testing }\end{array}$ & $\begin{array}{l}\text { All } \\
\text { Researcher responsible } \\
\text { for formalization, } \\
\text { validation, testing }\end{array}$ & $\begin{array}{l}\text { All } \\
\text { Participants involved in } \\
\text { all phases }\end{array}$ \\
\hline $\begin{array}{l}\text { Number } \\
\text { and } \\
\text { functions of } \\
\text { participants }\end{array}$ & $\begin{array}{l}\text { Per session } 2 \\
\text { participants: financial } \\
\text { manager and } \\
\text { accountant } \\
\text { senior management in } \\
\text { presentations }\end{array}$ & $\begin{array}{l}\text { On each site } 6 \text { or } 7 \\
\text { managers: demand, } \\
\text { product, logistic, supply } \\
\text { chain, distribution, } \\
\text { production leader and } \\
\text { production planner }\end{array}$ & $\begin{array}{l}\text { Per session } 5 \text { to } 13 \\
\text { managers maintenance }\end{array}$ \\
\hline $\begin{array}{l}\text { Sources of } \\
\text { information }\end{array}$ & Participants, database & Participants, database & Participants, database \\
\hline $\begin{array}{l}\text { Software } \\
\text { and other } \\
\text { materials }\end{array}$ & Vensim (CLD), Excel & Vensim & Dynaplan, Powersim \\
\hline
\end{tabular}




\begin{tabular}{|l|l|l|l|}
\hline $\begin{array}{l}\text { Time span } \\
\text { of project }\end{array}$ & May - Oct 2002 & Feb - August 2005 & March - Sept 2007 \\
\hline
\end{tabular}

Table 2. Process factors

Process case 1: Vinamul

In the first case, two sessions were used to construct the model. The first session involved the financial manager and accountant. The session started by a presentation of a small preliminary model constructed by the researcher. The model consisted of variables explaining trading profit. In the session a causal loop diagram (CLD) was constructed, describing the different elements of the financial forecasting process. Participants identified a specific model variable, raw material container costs, as a very volatile factor and thus difficult to model. In the second session the same persons participated. Most important for explaining trading profit was volume sold and gross sales. The final model organizes the variables in a hierarchy, starting from trading profit, the main categories of revenue and costs and lower levels of increasing detail. The causal loop diagram was then translated into formal model in the form of an Excel spreadsheet, using data from the financial system. Excel was chosen to formalize the model as data were available in spreadsheet format, Excel was used in financial planning in this company and financial managers and senior management were familiar with the tool. The top level view of the final model contains 33 variables. The structure is repeated for 29 key customers and simulates two years ahead in time on a monthly basis. The final model and recommendations were captured in a report and a presentation to senior management. The total project took about six months.

\section{Process case 2: Akzo Nobel}

In the second case the project started by visiting four different production sites of the client company. The modeler spent one week at each site. During the first visit (Cologne), production managers were interviewed to identify the central problem. The following visits (Adrian, Sege and Groot Ammers) were again used to interview production managers. Interviewees then constructed causal loop diagrams in two sessions at each site. In the last of the four site visits data were gathered for initial parameter estimation. The formal model was constructed in a fifth site (Darwen). Before the modeling sessions in Darwen, the researcher compared the qualitative models constructed at the different sites and interviewed participants. The first modeling session started with the presentation of a preliminary stocks and flows (s\&f) model which included the company's key performance indicators for the logistic process. During the session the main stocks and flows in the model were identified. At the end of the session participants spent some time on gathering data for formalizing the model. Results of this and subsequent sessions were reported back in the form of a workbook. The second session addressed the feedback loops in the model. After the session 
the researcher formalized the model. In the third and final meeting this model was presented and adjusted on the basis of participants' comments. The top level view of the final model contains 45 variables. Each plant produces a large variety of paints and its inventory contains thousands of stock keeping units. These products were thus categorized into three different product types and the model structure was repeated for each. The time horizon for the model was two years, run on a daily basis. The final model and recommendations were captured in a report and presented to senior management. The total project took about seven months.

\section{Process case 3: ONEgas}

In the third case the project started by a round of interviews. The first session addressed participants' expectations of the process followed by a short introduction of system dynamics. The participants, 13 in total, then identified the central problem variable. The Nominal Group Technique (individual notation of ideas on paper, followed by bringing ideas to the board in a round ribbon fashion) was used to identify model variables. No preliminary model was used, but the researcher concludes that this would have been useful to speed up the process. In the session a small causal loop diagram model was constructed. The initial problem variable, compliance (finishing maintenance projects before a set deadline) proved to be too distant from factors in the work process. Participants referred to a basic flow model of the work process, constructed in an earlier project. The group decided to use this model as a starting point and the focus shifted to identifying the subsequent phases in the work process and factors influencing these. Modelers and participants agreed that the specialized knowledge on the workflow would be most easily accessed in sessions with experts instead of in plenary sessions. In three sessions, two to three experts on the workflow elaborated the initial model. Similar to the Akzo Nobel case, results of this an following sessions were reported back in the form of a workbook. In the second plenary session 10 managers participated. Participants created an integrated stocks and flows model on the basis of the previous models. The researchers then used data from the SAP system to quantify the model. In SAP maintenance projects were subdivided into seven different priorities, and this structure was followed in the model. The next session was planned after the first simulation results were available. The third session took place around the time of a production shutdown and only five people participated. In this meeting the formal model was presented and simulation results shown. The participants agreed that the model captured the essence of the maintenance process. They wanted to proceed to use the model to test policy interventions in different scenarios. Three additional sessions in small groups helped in identifying interventions, scenario variables and key performance indicators. The fourth and final session presented conclusions and ways of improving the maintenance process. The top level view of the final model contains 45 variables. The structure is repeated for seven types of maintenance projects and simulates three years on a monthly basis. The final model and recommendations were 
captured in a report and a presentation to management. The total project took about seven months.

\section{Comparison to the generic modeling process}

One of the questions we address in this paper is whether the generic procedure for group model building needs to be adapted in an ERP context. As the notion of 'scripts' implies, the procedure for constructing system dynamics models with participants is very versatile. A wide choice of techniques is available to support specific parts of the modeling process. Nevertheless, a generic process for modeling is available in the form of Hines' approach (Otto \& Struben, 2004). Hines' approach includes the following steps:

- Diagnose the problem: gather and cluster problem variables, visualize problem by drawing the reference mode of behavior.

- Visualize model structure in a causal diagram, using the problem variables.

- Identify accumulations in the system, to form the stocks in the model.

- Construct the computer model. In this step most work is done by the modelers, with client participation limited to providing data such as numerical values and details of the work processes relevant to the problem at hand. Model structure and behavior is then explained to the client. Discussions with the client then lead to a series of model iterations, increasing confidence of the client in model calibration and validity.

- Simulate policies to test proposed interventions in the problem.

Comparing the three cases described above to these generic modeling steps, we see a number of recurrent themes in using group model building in an ERP environment. First, the participants in the sessions are primarily content experts. These are the people that have experience with the work process to be modeled. Final results are usually reported and presented to management, but senior managers are not present in the sessions. A management flight simulator, as used in the third case, is a way of engaging senior management that transfers insights in a time-efficient manner.

Second, only in the last case no preliminary model was used. Subsequently it proved difficult to find a central problem variable and focus for the model: compliance was proposed but used but proved too distant from daily work operations. Only after a basic flow model of the work process was identified to which participants were already familiar, did the modeling process take up speed. Vennix (1996) points out several advantages and disadvantages of using a preliminary model. Its use accelerates the modeling process as it focuses the initial discussion, avoiding time spent on finding the central relevant problem variable. An inexperienced facilitator will find it easier to guide these model-based discussions than to facilitate wide-ranging deliberations on what should be the focus of the model or even the project. A possible disadvantage of using a preliminary model is loss of ownership over 
modeling outcomes, as participants have not created the complete model themselves. However, the advantages seem to outweigh the disadvantages in this context. Models in an ERP context focus on a work process and participants usually are familiar with basic work flow diagrams. A preliminary model that captures the basic work flow in system dynamics terms is thus a logical starting point for a modeling project.

A third point is the type of model used. Although the phases in a workflow closely correspond to a stocks and flows model, initial models are in the form of causal diagrams in the first and third case. In the first case, the goal is to explain and predict trading profit, by specifying underlying components in more and more detail. Here causal relations are central and separating accumulations from flows might not have added much benefit in this case. In the third case the change to a stocks and flows model was made immediately after the first session as the work process became central to the modeling effort. A general conclusion is that when a work process is concerned, using a stocks and flows model seems most beneficial as it clearly shows different work phases. A related issue is that all cases start by using a qualitative model. Richardson (2006) provides guidelines on how to use formal preliminary models. Since in all cases data are available, using a formal model as a starting point is possible. This may speed up the modeling process further.

A fourth issue is client participation in model formalization. In Hines' approach the modeler has the lead here and checks results in sessions with participants. In the three cases, small groups were frequently used to conceptualize and find data on specific model parts. Participants also help the modeler in obtaining access to ERP data. Another striking point is that the similarity of model output to ERP data is an important face validity check for participants. Nevertheless, similarity to ERP data does not mean similarity to real life work processes. Frequently participants' experience and knowledge were needed to explain unexpected data in the ERP system. In this way participants' opinions and system data are clearly complementary.

Fifth, in all projects a model with relatively limited feedback complexity is created, but multiple units are captured in the structure ( 29 customers, three product categories, seven priorities, respectively). This is in line with Rouwette and Hoppenbrouwers' (2008) observation that system dynamics models are high in feedback complexity, while information systems models are high in detail complexity.

Finally, the first project seems to be different in comparison to the generic modeling process and both other cases. In the Vinamul case, the first session focuses on the system rather than the problem. The model does not contain feedback, which makes it possible to capture 
the formal model in Excel. Since this is a package participants are experienced with, this makes the model transparent and user friendly. According to Goedhart (2002: 44), the model 'should have the same structure as output of the forecasting model, for the ease of use, ease of interpretation and ease of implementation to forecasters, users and senior management.' Although group model building elements are used in the first case, the resulting formal model cannot be described as a system dynamics model as it does not contain feedback or accumulations.

\section{Outcome}

The main part of project outcomes concerns the intended results of group model building. By bringing the parties involved in the problem together and facilitating a joint modeling effort with these parties, group model building is expected to create a more shared view on the problem and on actions available to improve the situation (D. F. Andersen et al., 2007; Richardson \& Andersen, 1995; J. Vennix, 1996; J. A. M. Vennix, Akkermans, \& Rouwette, 1996). The system dynamics model created in this joint effort aims to explain problematic behavior by capturing the essential structure of the problem. Thus group model building aims for two sets of outcomes. The first are outcomes related to participants' direct involvement in modeling:

- improved quality of communication,

- mental model change or insight,

- consensus and

- commitment with regard to proposed actions in the problem.

These goals are important not only because they guarantee a high quality input for modeling but more so because each decision maker is thought to have a degree of discretion in implementing options: commitment of those involved in the problem is instrumental in implementing conclusions of the modeling effort.

The second set of outcomes concerns the technical goals of modeling. The model should be technically correct in the sense that it passes a set of validation tests (e.g. Forrester \& Senge, 1980). Simulations with the model should point to high leverage points for steering problematic behavior in the right direction, and these high leverage points should logically connect to proposed options in the real world. In addition to intended benefits of modeling, Rouwette et al. (2002) look at how evidence on outcomes is gathered by coding research design, data collection method, subjects, researchers, time span and feedback to the client. The following table lists the outcome variables for the three cases.

\begin{tabular}{|l|l|l|l|}
\hline & Goedhart (2002) & Ewalts (2005) & Venderbosch (2007) \\
\hline Research & Case study & Case study & One group pretest \\
\hline
\end{tabular}




\begin{tabular}{|c|c|c|c|}
\hline design & & & posttest \\
\hline $\begin{array}{l}\text { Data collection } \\
\text { method }\end{array}$ & $\begin{array}{l}\text { Session observations, } \\
\text { participatory } \\
\text { observation, interviews }\end{array}$ & $\begin{array}{l}\text { Post questionnaires, } \\
\text { session observation }\end{array}$ & $\begin{array}{l}\text { Pre and post } \\
\text { questionnaires, session } \\
\text { observation }\end{array}$ \\
\hline Subjects & 2 managers & 12 managers & 12 managers \\
\hline Researchers & Consultant & Consultant & Consultant \\
\hline Time span & Project & Project & Project \\
\hline $\begin{array}{l}\text { Feedback to } \\
\text { client }\end{array}$ & Report, presentation & Report, presentation & $\begin{array}{l}\text { Report, presentation, } \\
\text { MFS }\end{array}$ \\
\hline $\begin{array}{l}\text { Outcome } \\
\text { variables }\end{array}$ & $\begin{array}{l}\text { Learning, commitment, } \\
\text { responsibility for } \\
\text { continued use }\end{array}$ & $\begin{array}{l}\text { CICC } \\
\text { Comparison to regular } \\
\text { meetings } \\
\text { Elements GMB } \\
\text { Efficiency and success }\end{array}$ & $\begin{array}{l}\text { A, SN, PBC, I: PBC and } \\
\text { I change } \\
\text { CICC } \\
\text { Comparison to regular } \\
\text { meetings } \\
\text { Elements GMB } \\
\text { Efficiency and success }\end{array}$ \\
\hline
\end{tabular}

Table 3. Outcome factors

The first case uses a case study design to determine impact of the modeling project. The researcher gathers data by working in the client organization for the duration of the project, conducts interviews and observes sessions. The researcher is the same person as the modeler and the two managers involved in the sessions are the research subjects. The research is limited to the project (no measurements before or after the project are done). The feedback to the client consists of a report and a presentation. The master thesis (Goedhart, 2002: 53) contains conclusions on learning by subjects in the modeling project, commitment to results and expected continued use of the model: 'The implementation of the forecasting model is, because the involvement of users in the model building process, relatively easy. The finance department is aware of the model structure and functions.'

'The finance department is responsible for the total forecasting model. They fully control and own the forecasting model.'

The second project also uses a case study design. The researcher is the same person as the modeler and 12 managers involved in the sessions are the research subjects. The research is limited to the project. The feedback to the client consists of a report and a presentation. Data are gathered using project observations as well as a posttest questionnaire on impacts of the project. The questionnaire is based on work by Vennix and colleagues and described by Vennix and Rouwette (2000) and contains questions on communication, mental model change or insight, consensus, commitment (CICC), a comparison of the modeling sessions to 
regular meetings, the contribution of elements of modeling (for instance the facilitator or group discussion), project efficiency and success. Similar to the cases reported by Vennix and Rouwette (2000), results are in line with expectations.

The third project uses a one group pretest posttest design. Again, the researcher is the same person as the modeler and 12 managers involved in the sessions are the research subjects. The research is limited to the project (pretest and posttest are administered immediately before and after the project). The feedback to the client consists of a report, presentation and a management flight simulator. Data are gathered using project observations as well as a pretest and posttest questionnaire. The questionnaire consists of the CICC questionnaire described above and items based on work by Rouwette (2003). Rouwette proposes to conceptualize the impact of modeling, by focusing on the relation of modeling to changes in participants' behavior. Ajzen (2001) sees intentions as the immediate antecedent of behavior. Intentions (I) are in turn explained by attitudes toward behavior (A), subjective norms (SN) and perceived behavioral control (PBC). A similar conceptual model is used to explain user acceptance of ERP systems (Amoako-Gyampah, 2007; Nah et al., 2004). In the case on ONEgas, only intentions and perceived behavioral control are found to change over the course of the modeling interventions. Results of the CICC questionnaire are in line with expectations.

We can conclude that group model building in these cases indeed seems to have contributed to improved quality of communication, insight, consensus and commitment with regard to proposed actions in the problem. In the third case, where more specific measures were used, the project results in change in perceived behavioral control and intentions. Learning effects are illustrated by the fact that while all projects started out by focusing on one key performance indicator, important additional indicators were identified over the course of the modeling project identified. In this sense participants' problem view has broadened. The quality of the model is high judged in the eyes of participants.

\section{Conclusions}

We started this paper with a description of methodologies for fostering client involvement in ERP system implementation and deduction of interventions from large amounts of system data. Methodologies include approaches developed by ERP providers, the Balanced Scorecard, simulation and qualitative mapping. We identified group model building as a possible candidate for combining client involvement and identification of system improvements. We focused on two questions in particular: First, are the expected benefits of 
group model building realized in an ERP context? Second, does the generic procedure for group model building need to be adapted in this context?

With regard to outcomes, group model building in an ERP setting seems to result in positive effects such as learning, improved communication, consensus and commitment. The quality of the model is high judged in the eyes of participants. A limitation of this study is that actual implementation in the client organizations, and whether or not expected improvements in work processes were realized, are not considered. On the basis of three cases, we identified five points in which the generic group model building approach is adapted in ERP context:

1. Participants in the sessions are primarily content experts. Senior management is typically informed about the modeling outcomes via a report or presentation. A management flight simulator may be used to transfer insights to senior management in a time-efficient and engaging manner.

2. A preliminary model that captures the basic work flow in system dynamics terms is a logical starting point for an ERP modeling project.

3. A stocks and flows model corresponds most closely to participants' conceptualization of a work flow. A formal preliminary model may speed up the modeling process.

4. Similarity of model output to ERP data is an important face validity check for participants.

5. Projects tend to result in models of relatively limited feedback complexity but high detail complexity.

Our contribution to the literature on Enterprise Resource Planning is the description of a methodology for ERP system implementation and deduction of interventions from ERP data. We describe the essential elements of such a methodology by outlining context, process and outcome of three cases. Our contribution to the group model building literature is a clarification of where the standard process of participative modeling needs to be adapted when used in ERP systems modeling.

Further research may focus on two issues: how modeling of workflows is impacted by different organizational settings and on the extent of client involvement in group model building. Other organizational setting may include workflows in nonprofit settings and/ or multiple organization settings. Checking of tax forms is an example of a complicated work process managed by a single government organization. The criminal justice chain is a workflow involving police, public prosecution, judges and prison administration (Rouwette \& Vennix, submitted). The second issue concerns whether group model building is in essence not another way of adapting the organization to the proposed system. Methods developed by ERP providers, such as Accelerated SAP, operate on the premise that the organization will 
have to adapt to the system. Is the use of group model building really different in this respect, since it focuses on improvement of the existing work flow? Snabe and Größler (2006) report on a facilitated modeling project in which the strategic goal is already set. Participants are invited to identify the way in which these preset goals may be reached. How does this setting influence participants' expectations and evaluations of the modeling project?

\section{References}

Ackermann, F., \& Eden, C. (2005). Using causal mapping to support Information Systems development: some considerations. In V. Narayanan \& D. Armstrong (Eds.), Causal mapping for research in Information Technology (pp. 263-283). Hershey, PA: Idea Group Publishing.

Ajzen, I. (2001). Nature and operation of attitudes. Annual Review of Psychology, 52, 27-58.

Amoako-Gyampah, K. (2007). Perceived usefulness, user involvement and behavioural intention: an empirical study of ERP implementation. Computers in Human Behaviour, 23, 1232-1248.

Andersen, D., \& Richardson, G. (1997). Scripts for group model building. System Dynamics Review, 13, 107-129.

Andersen, D. F., Vennix, J. A. M., Richardson, G. P., \& Rouwette, E. A. J. A. (2007). Group model building: problem structuring, policy simulation and decision support. Journal of the Operational Research Society, 58(5), 691-694.

Banker, R., \& Kaufmann, R. (2004). The evolution of research on information systems. A fiftieth year survey of the literature in Management Science. Management Science, 50(3), 281-298.

Benders, J., Batenburg, R., \& Van der Blonk, H. (2006). Sticking to standards; technical and other isomorphic pressures in deploying ERP-systerns. Information \& Management, 43(2), 194-203

Checkland, P., \& Holwell, S. (1998). Information, systems and information systems. Chichester: Wiley.

Checkland, P., \& Poulter, J. (2006). Learning for action. A short definitive account of Soft Systems Methodology and its use for practitioners, teachers and students. Chichester: Wiley.

Davenport, T. H. (1998). Putting the enterprise into the enterprise system. Harvard Business Review, 76(4), 121-131.

Deenen, R. E. M. (2007a). Maintenance performance improvement with system dynamics: a corrective maintenance showcase. Paper presented at the ISDC, Athens, Greece.

Deenen, R. E. M. (2007b). Performance improvement of a corrective maintenance process. $A$ showcase of a system dynamics approach. TU Delft, Delft. 
Ewalts, D. (2005). Painting by numbers. Radboud University Nijmegen, Nijmegen.

Fahy, M. (2002). Enterprise Resource Planning Systems. London.

Forrester, J. (1958). Industrial dynamics. A major breakthrough for decision makers. Harvard Business Review, July- August, 37-66.

Forrester, J., \& Senge, P. (1980). Tests for building confidence in system dynamics models. TIMS Studies in the Management Sciences, 14, 209-228.

Goedhart, K. (2002). Bringing judgement into a forecasting model Radboud University Nijmegen, Nijmegen.

Größler, A., Thun, J. H., \& Milling, P. M. (2008). System dynamics as a structural theory in operations management. Production and operations management, 17(3), 373-384.

Hall, R. (2002). Enterprise resource planning systems and organizational change: transforming work organization? Strategic Change, 11, 263-270.

Hodgkinson, G., \& Clarkson, G. (2005). What have we learned from almost 30 years of research on causal mapping? Methodological lessons and choices for the Information Systems and Information Technology communities. In V. Narayanan \& D. Armstrong (Eds.), Causal mapping for research in Information Technology (pp. 46-80). Hershey, PA: Idea Group Publishing.

Howick, S., Ackermann, F., \& Andersen, D. (2006). Linking event thinking with structural thinking: methods to improve client value in projects. System Dynamics Review, 22(2), 113140.

Kaplan, R. S., \& Norton, D. P. (1996). The balanced scorecard: translating strategy into action. Boston, MA: Harvard Business School Press.

Lane, D. C. (1994). With a little help from our friends. How system dynamics and soft OR can learn from each other. System Dynamics Review, 10(2/3), $101-134$.

Luna-Reyes, L., Martinez-Moyano, I., Pardo, T., Cresswell, A., Andersen, D., \& Richardson, G. (2006). Anatomy of a group model-building intervention: building dynamic theory from case study research. System Dynamics Review, 22(4), 291-320.

Mabert, V. A., Soni, A., \& Venkataramanan, M. A. (2003). Enterprise resource planning: managing the implementation process. European Journal of Operational Research, 146(2), 302-314.

Milling, P. M. (1996). Modeling innovation processes for decision support and management simulation. System Dynamics Review, 12(3), 211-234.

Milling, P. M. (2002). Understanding and managing innovation processes. System Dynamics Review, 18(1), 73-86.

Muscatello, R., \& Parente, D. H. (2006). Enterprise Resource Planning (ERP): A Postimplementation Cross-Case Analysis. Information Resource Management Journal, 19(3), 61-80. 
Nah, F., Tan, X., \& The, S. H. (2004). An Empirical Investigation on End-Users' Acceptance of Enterprise Systems. Information Resource Management Journal, 17(3), 32-53.

Otto, P., \& Struben, J. (2004). Gloucester fishery : insights from a group modeling intervention. System Dynamics Review, 20(4), 287-312.

Pawson, R., \& Tilley, N. (1997). Realistic evaluation. London: Sage.

Richardson, G. (2006). Concept models. Paper presented at the International Conference of the System Dynamics Society, Nijmegen, The Netherlands.

Richardson, G., \& Andersen, D. (1995). Teamwork in group model building. System Dynamics Review, 11(2), 113-137.

Roberts, E. (1973). Strategies for effective implementation of complex corporate models. TIMS-ORSA Interfaces 8(1, part 1), 26-33.

Rouwette, E. A. J. A. (2003). Group model building as mutual persuasion. Nijmegen: Wolf Legal Publishers

Rouwette, E. A. J. A., \& Hoppenbrouwers, S. (2008). Collaborative systems modeling and group model building: a useful combination? Paper presented at the System Dynamics Conference Athens.

Rouwette, E. A. J. A., \& Vennix, J. A. M. (submitted). Modeling crime control in the Netherlands: insights on process. European Journal of Operational Research.

Rouwette, E. A. J. A., Vennix, J. A. M., \& Van Mullekom, T. (2002). Group model building effectiveness. A review of assessment studies. System Dynamics Review, 18(1), 5-45.

Snabe, B., \& Größler, A. (2006). System dynamics modelling for strategy implementation Case study and issues. Systems Research and Behavioral Science, 23(4), 467-481.

The Standish Group (2003). Chaos Chronicles Version 3.0. West Yarmouth, MA.

Trunick, P. (1999). ERP: Promise or pipe dream? Transportation and Distribution, 40(1), 2326.

Venderbosch, T. (2007). Using Group Model Building to optimize the maintenance process in an ERP environment at ONEgas. Radboud University Nijmegen, Nijmegen.

Vennix, J. (1996). Group model building. Facilitating team learning using system dynamics. Chichester: Wiley.

Vennix, J. A. M., Akkermans, H. A., \& Rouwette, E. A. J. A. (1996). Group model building to facilitate organisational change. An exploratory study. System Dynamics Review, 12(1), 3958.

Vennix, J. A. M., \& Rouwette, E. A. J. A. (2000). Group model building. What does the client think of it now? Paper presented at the International System Dynamics Conference, Bergen, Norway. 